Tables are all titled at the top with minimal explanations so that one has to refer constantly back to the text. Finally, the references are set out in a way which makes it difficult to disentangle individual papers by an author of several publications.

\section{References}

Central Youth Employment Executive (1965). The Foundry Industry. Choice of Careers No. 19, 2nd ed., p. 39. H.M.S.O., London.
Department of Trade and Industry (1972:. Digest of Pneumoconiosis Statistics 1970. H.M.S.O., London.

Hunter, D. (1969). The Diseases of Occupations, 5th ed., p. 987. English Universities Press, London.

Ministry of Labour (1962). Improving the Foundry Environment. Safety, Health and Welfare. New Series No. 17. H.M.S.O., London.

Lloyd Davies, T. A. (1971). Respiratory Disease in Foundrymen, Report of a Survey. H.M.S.O., London.

McLaughlin, A. I. G. (1950). Industrial Lung Diseases of Iron and Steel Foundry Workers. Ministry of Labour and National Service. H.M.S.O., London.

Received for publication April 22, 1972.

\title{
An unusual case of rosewood dermatitis of the genus Dalbergia (East Indian rosewood)
}

\author{
L. J. FINDLEY \\ Royal Infirmary, Sheffield
}

Dermatitis due to industrial irritants or sensitizers is responsible for a large proportion of occupational morbidity. More than $55 \%$ of prescribed diseases are due to non-infective dermatitis. For the correct diagnosis and assessment of these the dermatologist must obtain a full understanding of the industrial environment of affected workers.

\section{Case report}

The patient, a man aged 51, was referred to the Rupert Hallam Department of Dermatology in October 1970. He was complaining of an irritable rash which had been present for six weeks. On examination there was a dry, scaly, excoriated eruption which affected the dorsum of the feet, the back of the neck, and the front and back of the upper part of the trunk. The past medical history revealed a brief episode of infantile eczema. He had not received any treatment before attending the clinic.

The patient had been the director of a small saw-tool manufacturers for more than 20 years. His work involved contact with a variety of greases, mineral oils, and inorganic acids but he had not suffered previously from skin irritation. More detailed questioning revealed that an adjacent factory manufactured cutlery handles, and the extractor fan from this works covered the surrounding area with a fine sawdust. The patient also admitted using wood waste from this factory as firewood and had, therefore, handled pieces of wood and sawdust.

\section{Investigations}

The sawdust was identified as East Indian rosewood (Dalbergia latfolia). The patient showed a strongly positive reaction to a standard patch test with this dust and with a known sample of rosewood dust.

A visit to the area revealed several small old factories built around a rather Dickensian courtyard which was dominated by an extractor fan blowing fine rosewood sawdust over the surrounding buildings (Figure). The buildings housed small private light engineering firms whose employees worked continually exposed to fine rosewood sawdust. However, there was no evidence of 


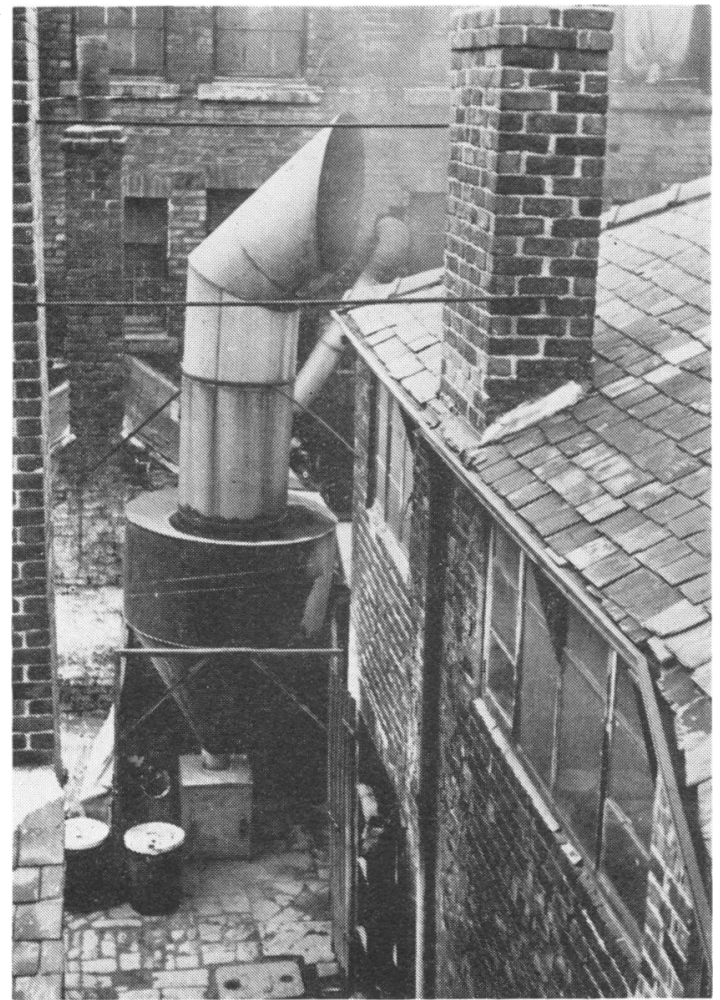

FIGURE Shows close proximity of extractor fan to occupied factory buildings.

skin disease in these people, nor symptoms that could be attributable to the dust. Twenty men working in the surrounding buildings were patch tested to a known sample of rosewood dust and to dust expelled by the extractor fan. Only one positive reaction was found in a man who, though working in an atmosphere of fairly concentrated rosewood dust, had no symptoms. Twenty medical students were similarly patch tested but all gave negative responses.

\section{Treatment and progress}

The patient was advised to avoid contact with the dust as much as possible and to apply dilute $1: 10$ betamethasone valerate (Betnovate) cream to the body twice a day and fluocinolone acetonide $0.25 \%$ (Ung. Synalar) to the hands twice a day. The patient's subsequent progress varied according to exposure to the dust. At one stage, after a short visit to his works, a severe recurrence of the dermatitis produced so much discomfort that he required admission to hospital and a short course of systemic steroids to curtail the condition. Unfortunately, for financial reasons, the patient was unable to give up work or move his factory to another area.

\section{Discussion}

A review of more than $\mathbf{4 0}$ wood species giving rise to symptoms was carried out by Sandermann and Barghoorn (1956). Since the last war there has been an increasing use of exotic timbers for furniture manufacture, etc., and this has given rise to a number of medical problems from the dusts produced in machining the wood. In several instances, from wood dusts producing dermatitis a specific sensitizing constituent has been extracted (Morgan and Wilkinson, 1965). The source of the wood implicated in this case was confirmed as Dalbergia latfolia or East Indian rosewood. Although recently other woods such as Machaerium scleroxylon have been substituted for rosewood, these have also given rise to outbreaks of dermatitis (Morgan, Orsler, and Wilkinson, 1968).

This case demonstrates some interesting features of industrial dermatitis. In the diagnosis of this it is usual to consider only substances with which the subject comes into contact routinely in his work. In the present case the environment was more important, and the cause was traced to atmospheric pollution from another factory. It is impossible to deny that the original sensitization might have occurred when the patient handled the rosewood for fire-lighting, but certainly he became so sensitive that even a visit of only a minute or two to his works produced an incapacitating recurrence. This pollution has prevented the patient from earning his living in his own factory, and under the Public Health Act 1936, Section 91, the local authority has powers to deal with this situation as it constitutes a statutory nuisance. However, the problem has been solved as, with the help of the local authority, the patient was offered alternative accommodation for his factory in another party of the city.

I am grateful to Dr. I. B. Sneddon for permission to report this case and for his valuable advice.

\section{References}

Morgan, J. W. W., Orsler, R. J., and Wilkinson, D. S. (1968). Dermatitis due to the wood dusts of Khaya anthotheca and Machaerium scleroxylen. Brit. J. industr. Med., 25, 119-125.

- , and Wilkinson, D. S. (1965). Dermatitis produced by wood. International Union Forestry Research Organisation Meeting.

Sandermann, W., and Barghoorn, A. W. (1956). Gesundheitsschädigende Hölzer. Holz als Roh-u.-Werkstoff, 14, 37-40 and 87-94.

Received for publication August 12, 1971. 